23

\title{
Зажигание каменных углей различных стадий метаморфизма лазерными импульсами в режиме свободной генерации
}

\author{
(С) Б.П. Адуев, Д.Р. Нурмухаметов, Я.В. Крафт, З.Р. Исмагилов \\ Федеральный исследовательский центр угля и углехимии Сибирского отделения РАН, \\ 650000 Кемерово, Россия \\ e-mail: lesinko-iuxm@yandex.ru
}

Поступила в редакцию 11.11.2019 г.

В окончательной редакции 04.12.2019 г.

Принята к публикации 06.12.2019 г.

\begin{abstract}
Проведено исследование лазерного зажигания $(1064 \mathrm{~nm}, 120 \mu \mathrm{s})$ каменных углей марок ДГ, Г, Ж и К. Для всех марок углей обнаружены три последовательные стадии зажигания, характеризующиеся пороговыми плотностями энергии излучения, имеющие характерные значения для каждой марки угля.
\end{abstract}

Ключевые слова: уголь, лазер, зажигание, летучие вещества, степень углефикации, коксовый остаток.

DOI: $10.21883 /$ OS.2020.03.49073.302-19

\section{Введение}

Физические методы зажигания угольной пыли, хотя и разрабатываются, однако пока не получили широкого распространения. Лазерное (непрерывное или импульсное) излучение в перспективе может быть использовано для розжига пылеугольного топлива в промышленных печах вместо применяемого в настоящее время мазута. В случае решения этой задачи возможно получение значительного экономического и экологического эффекта. Детальное изучение условий зажигания пылеугольного топлива представляет интерес для разработки методов предотвращения взрывов угольной пыли в шахтах или методов стабилизации пламени в пылеугольных топках [1-3]. Изучение этих процессов с использованием лазерного зажигания имеет ряд преимуществ: легкий оптический доступ к частицам, возможность прямого наблюдения воспламенения частиц. Работы по лазерному зажиганию углей ведутся давно с использованием неодимового и $\mathrm{CO}_{2}$-лазеров, работающих в импульсном и непрерывном режиме [4-9]. Однако детальное исследование различных стадий зажигания в этих работах не выполнено.

В [10,11] проведены первые эксперименты по зажиганию бурого и длиннопламенного углей Кузнецкого угольного бассейна при лазерном воздействии в режиме свободной генерации (длина волны излучения $1064 \mathrm{~nm}$, длительность лазерного импульса $120 \mu \mathrm{s})$. Были экспериментально обнаружены 3 стадии воздействия лазерного излучения на бурый (Б) и длинно-пламенный газовый (ДГ) угли: первая стадия связана с нагревом поверхности образца; вторая стадия связана с образованием и воспламенением летучих веществ; третья стадия связана с зажиганием нелетучего остатка. Показано, что каждая стадия имеет ярко выраженный пороговый характер.
В настоящей работе продолжены аналогичные исследования на расширенном наборе образцов каменных углей Кузнецкого угольного бассейна.

\section{Объекты и методика}

Использовались угли Кузнецкого угольного бассейна различных стадий метаморфизма: длиннопламенный газовый (ДГ), газовый $(\Gamma)$, жирный (Ж) и коксовый $($ К).

Угли подвергались помолу на шаровой мельнице. После помола отбиралась фракция частиц угля с размером $\leq 63 \mu$ m путем просеивания через сито. Результаты технического анализа углей приведены в табл. 1. В эксперименте использовались образцы насыпной плотностью $0.5 \mathrm{~g} / \mathrm{cm}^{3}$, массой $10 \mathrm{mg}$, которые помещались в медный колпачок диаметром $5 \mathrm{~mm}$ и глубиной $2 \mathrm{~mm}$.

Схема эксперимента и подробное описание установки приведено в [10].

\section{Экспериментальные результаты}

Проведено исследование порогов воспламенения и зажигания образцов углей. Десять образцов каждой конкретной марки угля последовательно облучались единичным импульсом лазера определенной энергии и с помощью фотоумножителя регистрировалось свечение образца. Вероятность воспламенения определялась как $p=n / 10$, где $n-$ число зарегистрированных осциллографом вспышек. Далее энергия излучения увеличивалась и эксперимент повторялся. В итоге измерялась зависимость вероятности появления вспышки от плотности энергии излучения лазера. За порог зажигания принимали плотность энергии $H_{\mathrm{cr}}$, соответствующей $50 \%$ вероятности появления вспышки. Эксперименты повторялись с применением всех марок угля, перечисленных в предыдущем разделе. 


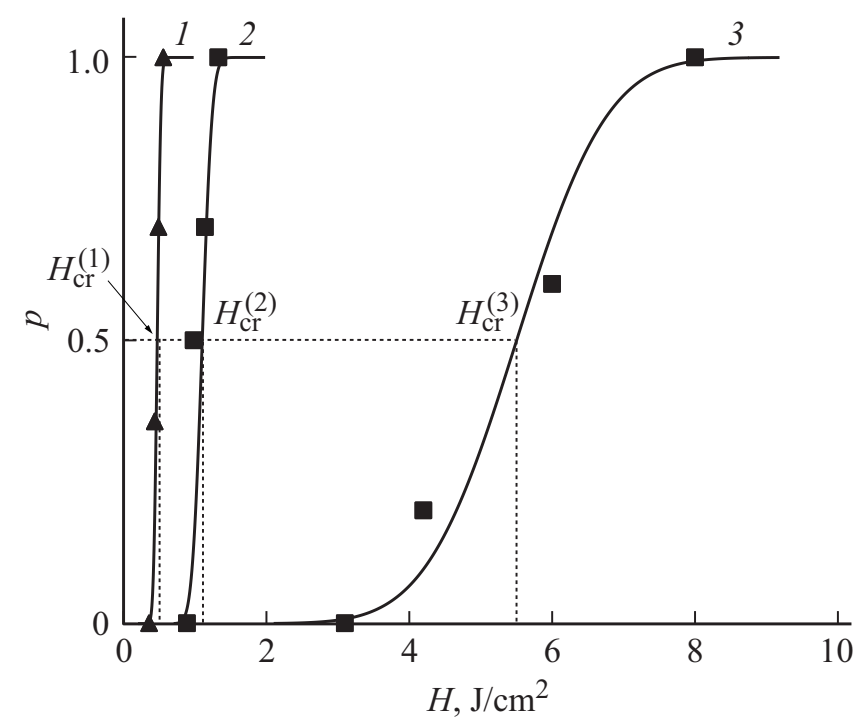

Рис. 1. Зависимость вероятности зажигания от плотности энергии лазерного излучения для угля марки Ж. 1 - кривая частости, соответствующая нагреву поверхности и воспламенению микровыступов на поверхности частиц угля. 2 - кривая частости, соответствующая выходу и воспламенению летучих веществ в газовой фазе. 3 - кривая частости, соответствующая зажиганию коксового остатка частиц угля.

Таблица 1. Результаты технического анализа углей

\begin{tabular}{l|c|c|c|c}
\hline Марка угля (месторождение) & $W^{a}, \%$ & $A^{d}, \%$ & $V^{\mathrm{daf}}, \%$ & $C^{\mathrm{daf}}, \%$ \\
\hline ДГ (Соколовское) & 4.0 & 4.6 & 40.2 & 79 \\
\hline Г (Ленинское) & 2.9 & 38.4 & 38.0 & 81 \\
\hline Ж (Никитинское) & 1.2 & 4.8 & 34.1 & 88 \\
\hline К (Киселевско-Прокопьевское) & 1.0 & 4.9 & 21.2 & 90
\end{tabular}

Примечание. $W^{a}-$ влага аналитической пробы, $A^{d}-$ зольность аналитической пробы, $V^{\text {daf }}-$ выход летучих веществ; $C^{\text {daf }}-$ содержание углерода в аналитической пробе.

Таблица 2. Пороги зажигания углей на различных стадиях

\begin{tabular}{c|c|c|c}
\hline Марка угля & $H_{\mathrm{cr}}^{(1)}, \mathrm{J} / \mathrm{cm}^{2}$ & $H_{\mathrm{cr}}^{(1)}, \mathrm{J} / \mathrm{cm}^{2}$ & $H_{\mathrm{cr}}^{(1)}, \mathrm{J} / \mathrm{cm}^{2}$ \\
\hline ДГ & 0.39 & 1.6 & 2.4 \\
$\Gamma$ & 0.45 & 1.85 & 3.3 \\
Ж & 0.47 & 1.1 & 5.5 \\
К & 0.35 & 0.9 & 10.0
\end{tabular}

По характеру зарегистрированных осциллограмм свечения для всех марок исследованных углей можно выделить три порога $H_{\text {cr }}$, приводящих к различным процессам в образцах.

Значения $H_{\text {cr }}$ для всех исследованных марок углей представлены в табл. 2. На рис. 1 для примера приведены зависимости вероятности зажигания от плотности энергии для угля марки Ж, по которым определялись пороги $H_{\text {cr }}$ (кривые частости). На рис. 2 приведены осциллограммы, зарегистрированные фотоумножителем, соответствующие свечению пламен угля марки Ж при вероятности $p=0.5$ для трех вышеуказанных процессов. Качественно аналогичные кривые частости и соответствующие им зарегистрированные осциллограммы свечения получены для всех марок углей.

Отметим, что при плотностях энергии, соответствующих $H_{\mathrm{cr}}^{(1)}$, над поверхностью образцов наблюдается невысокое пламя высотой $h \leq 1 \mathrm{~mm}$, при достижении $H_{\mathrm{cr}}^{(2)}$ высота пламени достигает $h \sim 3-5 \mathrm{~mm}$ над поверхностью образцов. При достижении $H_{\mathrm{cr}}^{(3)}$ для всех марок углей наблюдается вертикальное пламя высотой до $10 \mathrm{~cm}$. Аналогичные процессы наблюдались нами ранее при исследовании лазерного зажигания угля марки 2Б [11].

На рис. $3, a, b$ представлены зависимости первого порога зажигания $H_{\mathrm{cr}}^{(1)}$ от содержания летучих веществ и степени углефикации различных марок углей. Как видно по рис. $3, a$, с увеличением содержания летучих веществ наблюдаются практически постоянные значения $H_{\mathrm{cr}}^{(1)}=0.35-0.45 \mathrm{~J} / \mathrm{cm}^{2}$ с большим статистическим разбросом. Аналогичное поведение $H_{\mathrm{cr}}^{(1)}$ наблюдается при уменьшении степени углефикации.

На рис. $4, a, b$ представлены аналогичные зависимости для $H_{\mathrm{cr}}^{(2)}$. Как видно по рис. $4, a$, с увеличением содержания летучих веществ наблюдается рост $H_{\mathrm{cr}}^{(2)}$. С уменьшением степени углефикации наблюдается линейный рост $H_{\mathrm{cr}}^{(2)}$ (рис. $\left.4, b\right)$.

На рис. $5, a, b$ представлены аналогичные зависимости для $H_{\mathrm{cr}}^{(3)}$. С увеличением содержания летучих веществ наблюдается линейный спад $H_{\mathrm{cr}}^{(3)}$ для каменных углей (рис. 5,a). Аналогичные зависимости $H_{\mathrm{cr}}^{(3)}$ наблюдаются с уменьшением степени углефикации (рис. $5, b$ ).

В следующей серии экспериментов исследована зависимость осциллограмм свечения пламен образцов от плотности энергии лазера для трех обнаруженных процессов. Для первого процесса в интервале плотностей энергий от $H_{\mathrm{cr}}^{(1)}$ вплоть до плотностей, соответствующих началу второго процесса, длительность свечения практически повторяет длительность импульса лазера.

Для интервала плотностей энергий от $H_{\mathrm{cr}}^{(2)}$ до $6 \cdot H_{\mathrm{cr}}^{(2)}$ для осциллограмм свечения, соответствующих второму процессу, наблюдается уменьшение длительности свечения. При достаточно больших плотностях энергии большая часть светосуммы высвечивается уже во время длительности импульса, о чем свидетельствует рост амплитуды свечения во время воздействия импульса облучения, и лишь незначительная часть высвечивается в миллисекундном временном интервале.

В качестве примера на рис. 6 приведены осциллограммы свечения пламен для угля марки Ж в диапазоне плотностей энергии $H=1.1-7 \mathrm{~J} / \mathrm{cm}^{2}$.

Измерение осциллограмм свечения пламен углей, соответствующих плотностям энергий $H \geq H_{\mathrm{cr}}^{(3)}$, пока- 

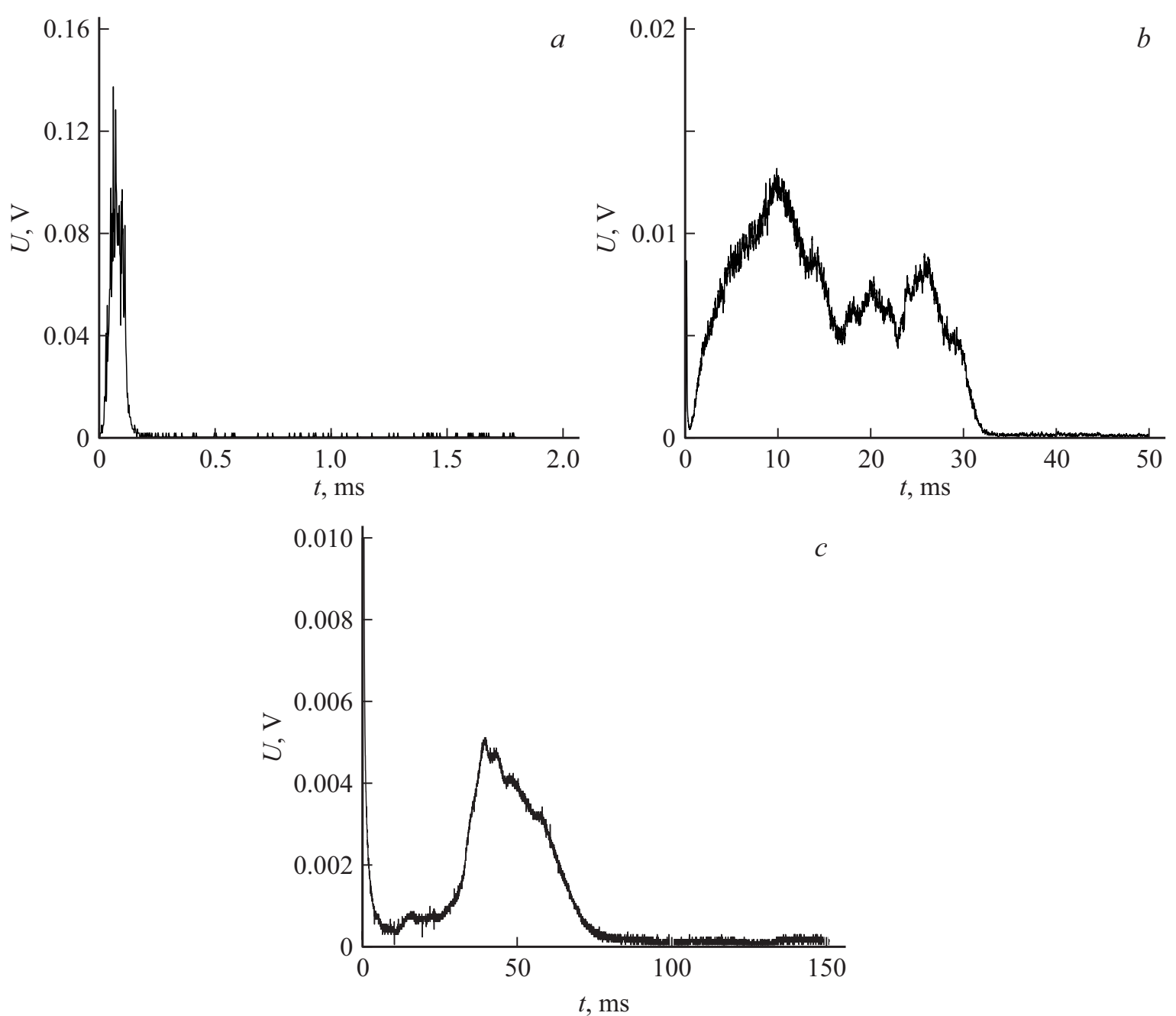

Рис. 2. Осциллограммы свечения угля марки Ж, соответствующие трем стадиям зажигания. $a-H_{\mathrm{cr}}^{(1)}=0.47 \mathrm{~J} / \mathrm{cm}^{2} . b-$ $H_{\mathrm{cr}}^{(2)}=1.85 \mathrm{~J} / \mathrm{cm}^{2} . c-H_{\mathrm{cr}}^{(3)}=5.5 \mathrm{~J} / \mathrm{cm}^{2}$.
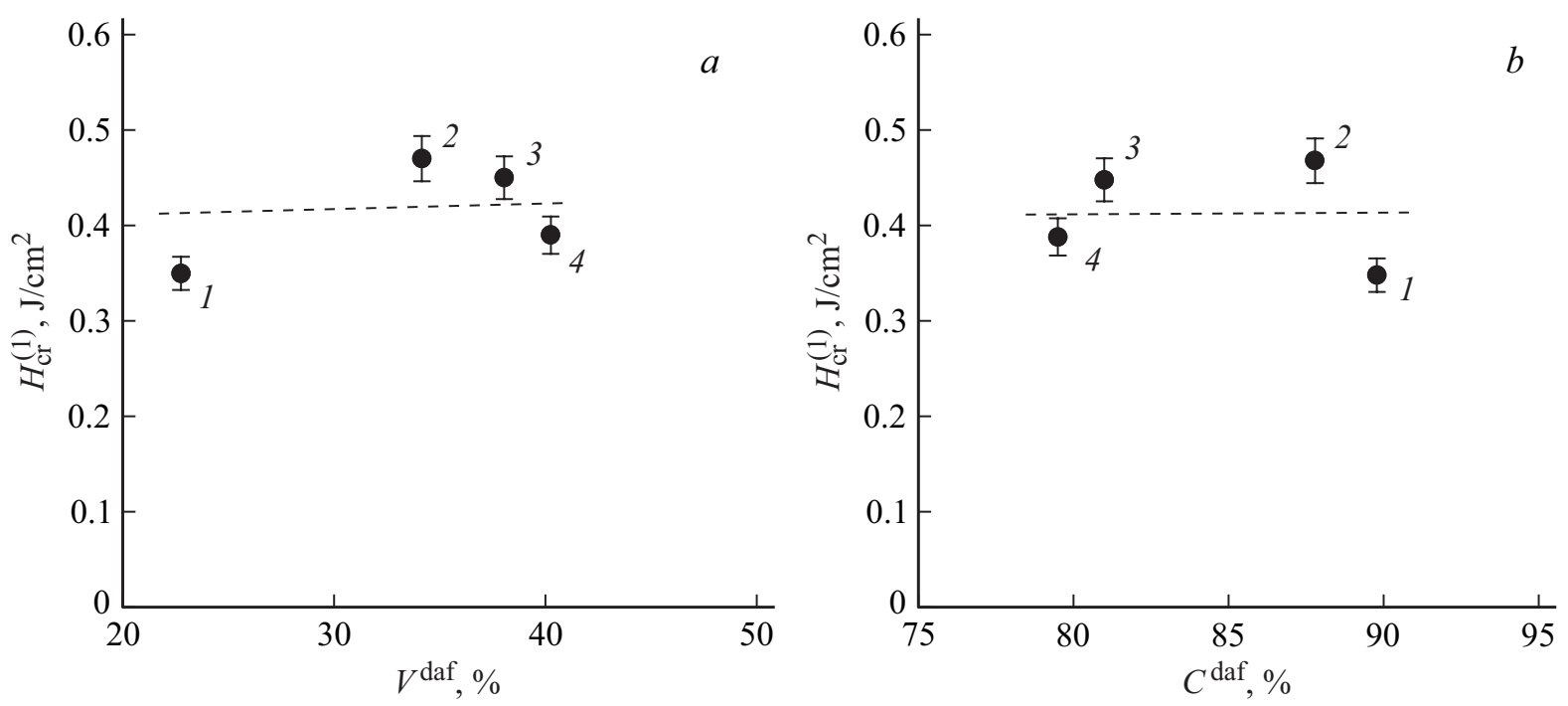

Рис. 3. Зависимость первого порога зажигания $H_{\mathrm{cr}}^{(1)}$ углей марки К $(1)$, Ж (2), Г (3), ДГ (4) от содержания летучих веществ в угле $(a)$ и от степени углефикации $(b)$. 

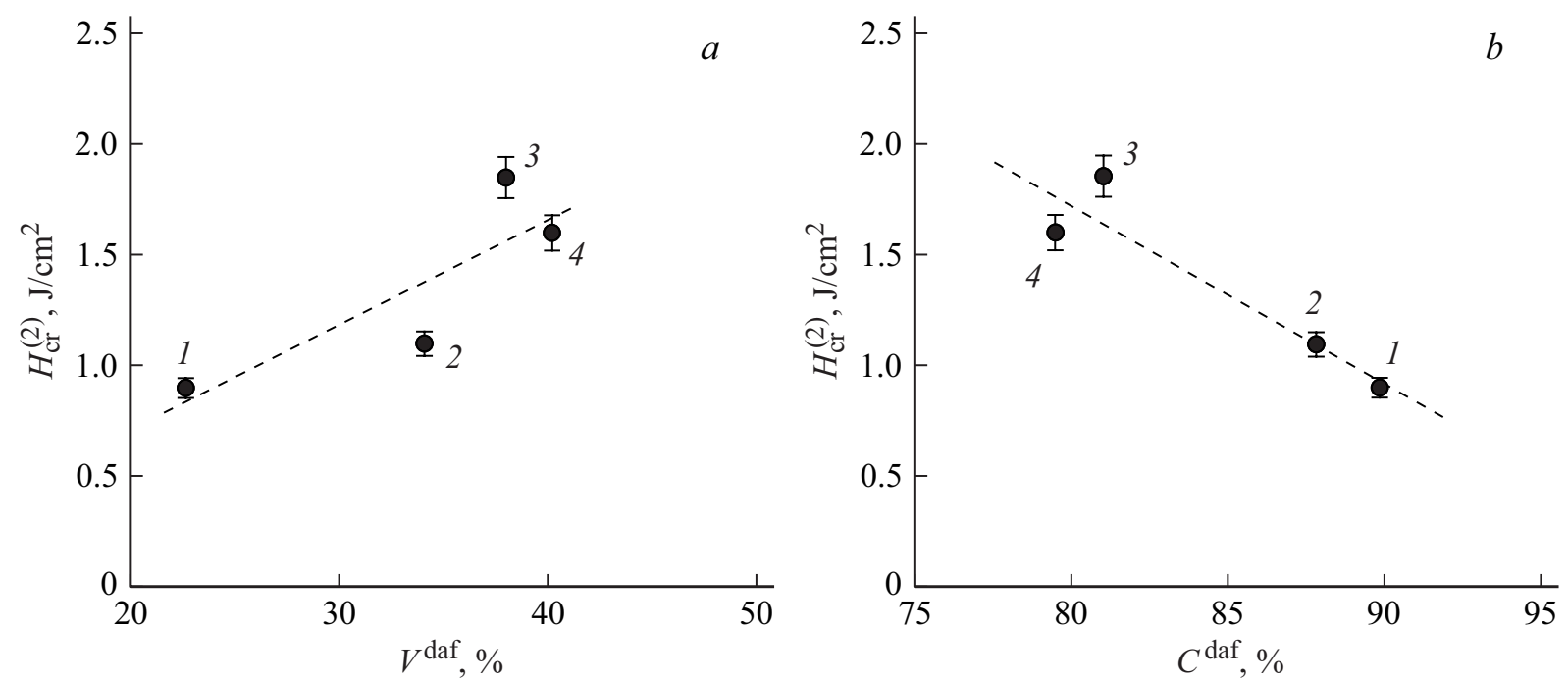

Рис. 4. Зависимость второго порога зажигания $H_{\mathrm{cr}}(2)$ углей марки К (1), Ж (2), Г (3), ДГ (4) от содержания летучих веществ в угле $(a)$ и от степени углефикации $(b)$.
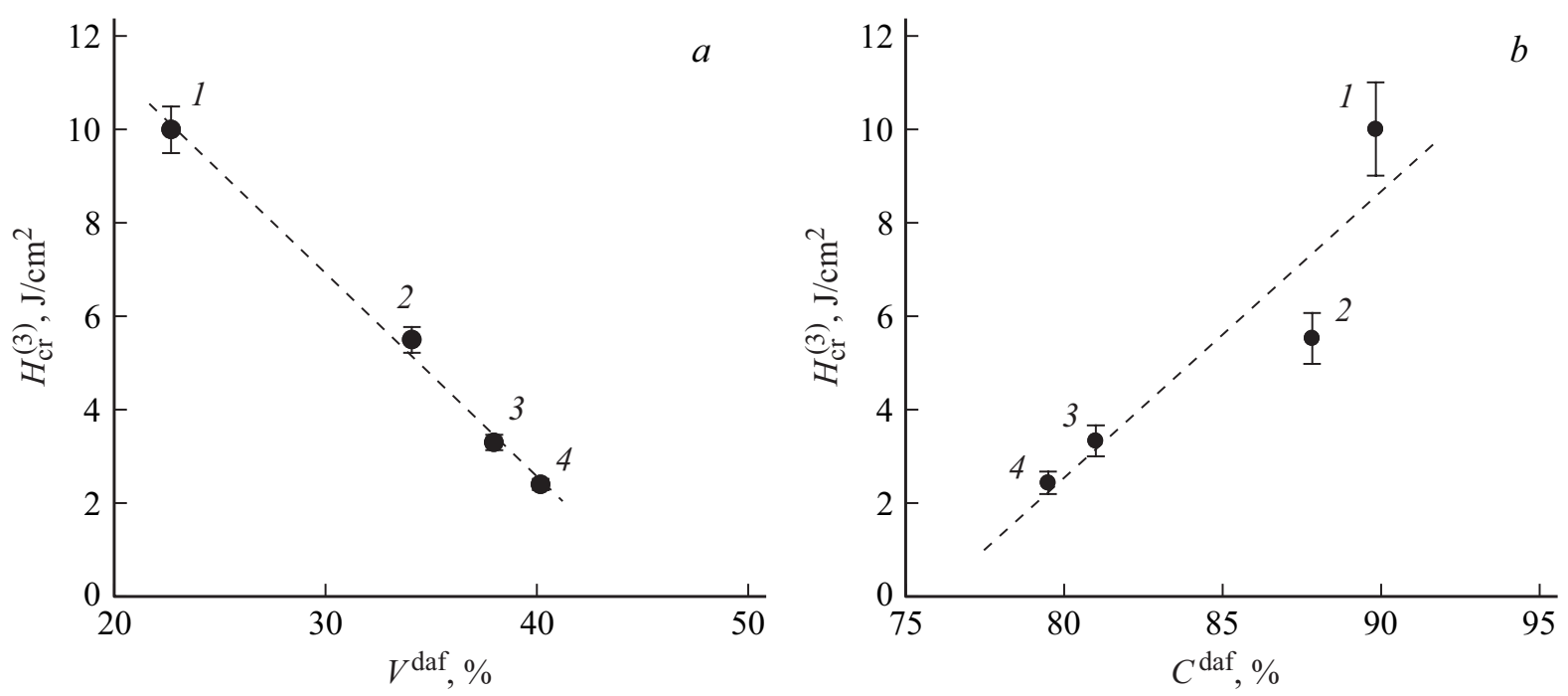

Рис. 5. Зависимость третьего порога зажигания $H_{\mathrm{cr}}(3)$ углей марки К (1), Ж (2), Г (3), ДГ (4) от содержания летучих веществ в угле $(a)$ и от степени углефикации $(b)$.

зало, что длительность горения лежит во временном интервале 50-70 ms (для угля марки ДГ до $100 \mathrm{~ms}$ ) и практически не зависит от плотности энергии излучения, хотя форма импульса и длительность процесса горения флуктуируют в указанном интервале даже при фиксированной плотности энергии. В качестве примера на рис. 7 приведены осциллограммы свечения пламен для угля марки Ж в интервале плотностей энергии $6-15 \mathrm{~J} / \mathrm{cm}^{2}$.

\section{Обсуждение результатов}

Рассмотрим зависимости порогов зажигания от содержания летучих веществ и степени углефикации исследованных марок углей для каждого из измеренных порогов зажигания $H_{\mathrm{cr}}^{(1)}, H_{\mathrm{cr}}^{(2)}, H_{\mathrm{cr}}^{(3)}$ (рис. 3-5). Первую стадию, соответствующую порогу зажигания $H_{\mathrm{cr}}^{(1)}$, ранее мы связывали с нагревом поверхности частиц $[10,11]$. В работе [3] показано, что первоначальным процессом при нагревании угольных частиц при поглощении лазерного излучения является зажигание микровыступов на поверхности частиц. В пользу этого вывода свидетельствуют результаты наших экспериментов (см. предыдущий раздел), в которых обнаружено пламя высотой $h \leq 1 \mathrm{~mm}$ над поверхностями частиц углей различных марок. Этот процесс связан с размерами частиц и геометрией их поверхностей, которые имеют большой статистический разброс и в результате дают измеряемые в эксперименте значения $H_{\mathrm{cr}}^{(1)}=0.35-0.45 \mathrm{~J} / \mathrm{cm}^{2}$. Возможно, именно этот процесс дает определяющий 


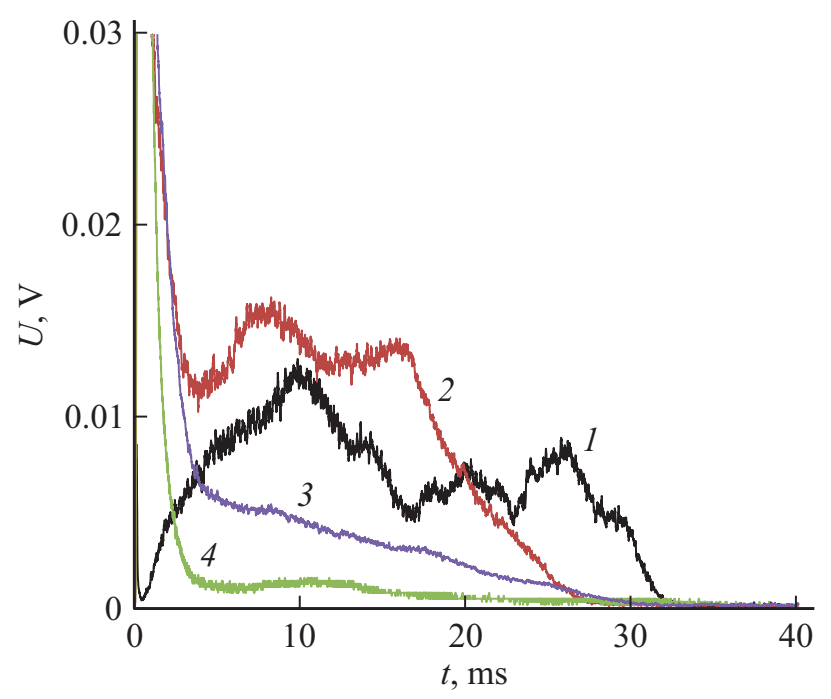

Рис. 6. Осциллограммы свечения пламени угля марки Ж на второй стадии при воздействии лазерными импульсами с плотностями энергии: $H_{1}=1.1 \mathrm{~J} / \mathrm{cm}^{2}(1), H_{2}=2 \mathrm{~J} / \mathrm{cm}^{2}$ (2), $H_{3}=3.5 \mathrm{~J} / \mathrm{cm}^{2}(3), H_{4}=7 \mathrm{~J} / \mathrm{cm}^{2}(4)$.

вклад в $H_{\mathrm{cr}}^{(1)}$ и приводит к слабой зависимости (либо к ее отсутствию) от содержания летучих веществ и степени углефикации. В результате воспламенения микровыступов за время лазерного импульса происходит нагрев поверхности частиц. В нашей работе [11] измерялась температура нагрева поверхности частиц бурого угля методом импульсной спектральной пирометрии. По измеренному тепловому спектру излучения, возникающему непосредственно во время импульса излучения при достижении $H=H_{\mathrm{cr}}^{(1)}$, определена температура $T=3100$ K. Предварительные эксперименты показали, что на каменных углях температура нагрева поверхности достигает таких же значений. Результаты будут представлены в дальнейшем в отдельной работе.

В работе [4] с помощью модельных расчетов показано, что во время воздействия лазерного импульса длительностью $150 \mu \mathrm{s}$ происходит нагрев поверхности угольных частиц размером $136 \mu \mathrm{m}$ до $T_{1}>2000 \mathrm{~K}$. За время $\sim 600 \mu$ s от начала облучения происходит уменьшение температуры до $T_{2} \approx 1500 \mathrm{~K}$ и выравнивание ее по объему частицы. При уменышении размера частиц до $96 \mu \mathrm{m}$ температура $T_{2}$ достигает равновесия за $220 \mu \mathrm{s}$ [4]. Естественно, цифры будут зависеть от конкретных теплофизических параметров и размеров частиц. Однако из этих расчетов можно сделать вывод, что если $T_{2}$ меньше температуры воспламенения, то процесс после окончания лазерного импульса затухает, что и наблюдается в интервале плотностей энергии $H_{\mathrm{cr}}^{(1)} \leq H<H_{\mathrm{cr}}^{(2)}$ в наших экспериментах. При достижении плотности энергии значений $H_{\mathrm{cr}}^{(2)}$ инициируется второй этап. После окончания лазерного импульса наблюдается спад интенсивности свечения за время $\sim 300 \mu \mathrm{s}$, затем начинается рост интенсивности свечения. Можно сделать вывод, что при поглощении энергии излучения, соответствующей $H_{\mathrm{cr}}^{(2)}$, после выравнивания температуры по объему частиц $T_{2}$ оказывается достаточной для инициирования термохимической реакции, приводящей ко второму процессу в изучаемых марках углей. Для других марок углей начало роста интенсивности свечения при достижении соответствующих $H_{\mathrm{cr}}^{(2)}$ происходит в аналогичном временном интервале.

Второй порог $H_{\mathrm{cr}}^{(2)}$ растет с увеличением содержания летучих веществ и соответственно снижается с ростом степени углефикации (рис. 4). Ранее мы связывали процессы, соответствующие $H_{\mathrm{cr}}^{(2)}$ в углях марок 2Б и ДГ, с выходом и воспламенением летучих веществ $[10,11]$. Спектрально-кинетические и масс-спектрометрические измерения, проведенные на буром угле, подтвердили это предположение [11]. В спектрах излучения в миллисекундном временном интервале обнаружено свечение пламени $\mathrm{CO}$ и возбужденных молекул $\mathrm{H}_{2}$ и $\mathrm{H}_{2} \mathrm{O}$ [11].

Для объяснения наблюдаемых закономерностей мы предлагаем следующую модель процесса. С нашей точки зрения, инициирование термохимической реакции связано с поглощением энергии лазерного излучения. Показатели поглощения углей $k$ не измерялись, однако известно, что в петрографии используют измерения на просвет шлифов бурого и низкометаморфизованных углей [12]. С ростом углефикации шлифы уже не прозрачны в проходящем свете, поэтому исследуются на отражение. Эти факты, по крайней мере, на качественном уровне свидетельствуют о росте показателя поглощения с увеличением степени углефикации. Температура лазерного зажигания углей $T_{3}$ в ряду метаморфизма почти не изменяется [13], следовательно, и при зажигании различных углей для достижения $T_{3}$ объемная плотность поглощенной энергии $Q_{v}$ изменяется слабо. С другой стороны, $Q_{v} \sim H \cdot k(1)$. Отсюда следует, что с увеличением степени углефикации и возрастанием $k$ уменьшается $H_{\mathrm{cr}}^{(2)}$.

Результаты, представленные на рис. 6, укладываются в рамки предложенной гипотезы. С ростом $H$ для данной марки угля увеличивается поглощенная энергия $Q_{v}$ согласно (1). Рост $Q_{v}$ приводит к большему нагреву частиц, что увеличивает скорость термохимической реакции, приводящей к выходу и воспламенению летучих веществ.

На третьем этапе с ростом степени углефикации и уменьшением содержания летучих веществ в ряду углей от марки ДГ до марки К наблюдается увеличение порога зажигания $H_{3}$ (рис. 5), который мы связываем с зажиганием коксового остатка. Таким образом, наблюдается качественно противоположная зависимость той, которая наблюдалась на втором этапе при зажигании летучих веществ. Аналогичный характер зависимости порогов зажигания с ростом углефикации наблюдали в работах $[1,4,14]$. В этих работах не выделяли второй процесс, поэтому исследовался практически $H_{\mathrm{cr}}(3)$ или величина, ему пропорциональная. Объяснения характера 

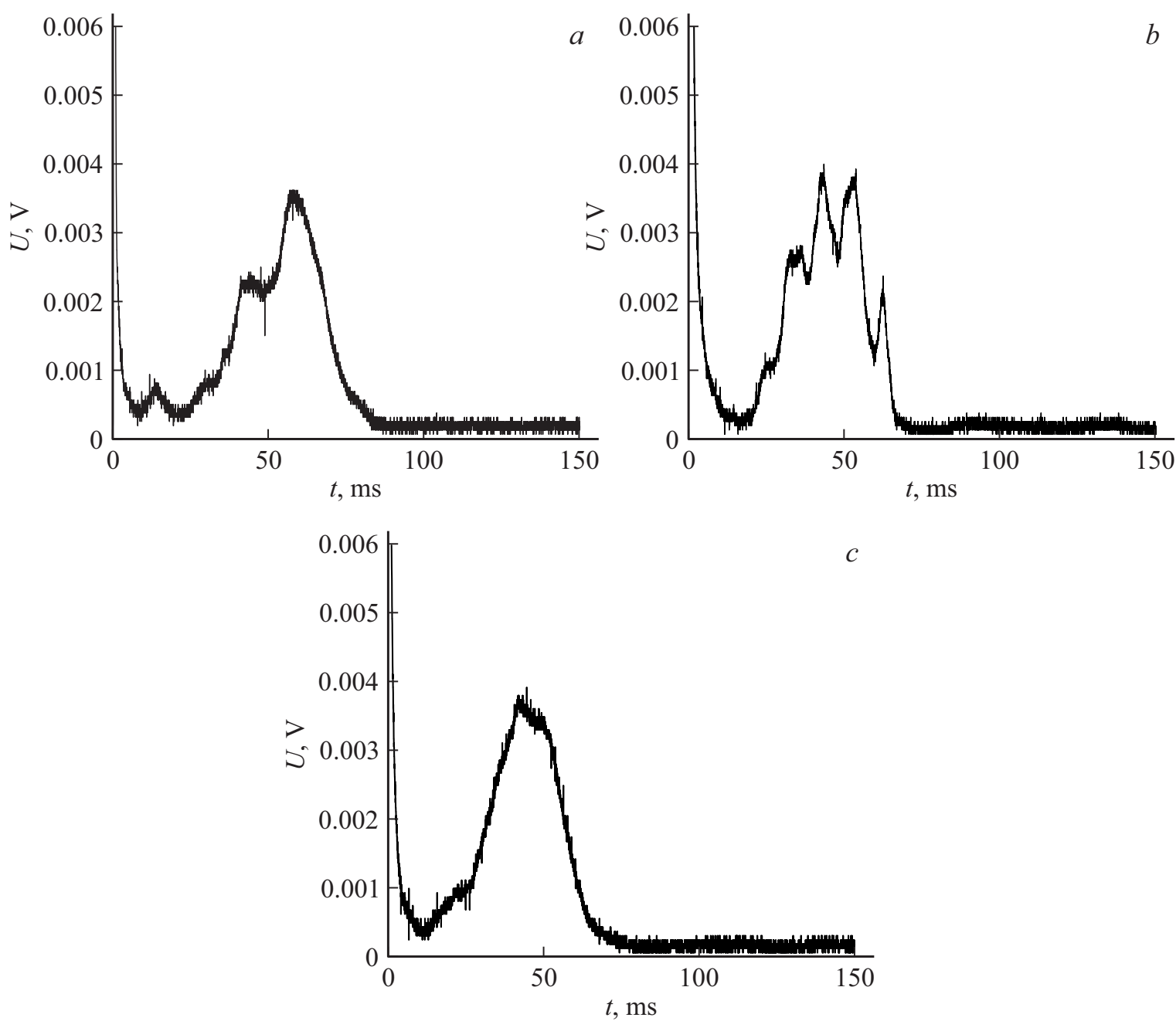

Рис. 7. Осциллограммы свечения пламени угля марки Ж на третьей стадии при воздействии лазерными импульсами с различными плотностями энергии: $a-6 \mathrm{~J} / \mathrm{cm}^{2}, b-8.5 \mathrm{~J} / \mathrm{cm}^{2}, c-15 \mathrm{~J} / \mathrm{cm}^{2}$.

зависимости $H_{\mathrm{cr}}$ от содержания летучих веществ (степени углефикации) в работах $[1,4,14]$ не дается, а только констатируется сам факт. Мы предлагаем следующее объяснение наблюдаемой зависимости $H_{\mathrm{cr}}^{(3)}$ от степени углефикации. На третьем этапе нагрев угольных частиц до температуры зажигания осуществляется в результате действия двух факторов:

1. Нагрев частиц углей в результате сгорания газовой фазы. Сгорание газовой фазы при плотностях энергии $H_{\mathrm{cr}}^{(3)}$ происходит во время импульса излучения, как показано выше (рис. 6).

2. Нагрев за счет поглощения энергии лазерного импульса.

C увеличением степени углефикации уменьшается масса сгоревших летучих веществ, что соответственно приводит к относительно меньшему нагреву угольных частиц. Для достижения температуры зажигания требуется увеличение энергии лазерного импульса, что и приводит к наблюдаемой зависимости $H_{\mathrm{cr}}^{(3)}$ от степени углефикации. Таким образом, инициирование термохи- мических реакций, приводящих к зажиганию коксового остатка происходит в результате нагрева частиц пламенем летучих веществ и поглощением лазерного излучения.

Известно, что горение коксового остатка включает ряд последовательно-параллельных химических реакций $[15,16]$. Независимость времени горения от увеличения плотности излучения $H>H_{\mathrm{cr}}^{(3)}$ указывает на то, что в данном случае для начала последовательности термохимических реакций требуется минимальное значение $H=H_{\mathrm{cr}}^{(3)}$ для инициирования первой реакции, а дальнейшее увеличение $H$ не влияет на скорость горения частицы, которая, по-видимому, лимитируется последующими химическими реакциями.

\section{Выводы}

1. При лазерном воздействии на угли марок ДГ, Г, Ж, К насыпной плотности $0.5 \mathrm{~g} / \mathrm{cm}^{3}$ выделено три стадии воспламенения, имеющие пороговый характер. Первая 
стадия связана с нагревом поверхности и зажиганием микровыступов на частицах угля. Вторая стадия связана с выходом и воспламенением летучих веществ. Третья - с зажиганием коксового остатка.

2. Измерены пороги зажигания для всех марок углей на каждой стадии. Порог на первой стадии слабо изменяется для всех углей в ряду метаморфизма. Второй порог уменьшается при возрастании степени углефикации и уменьшении содержания летучих веществ. Третий увеличивается с возрастанием степени углефикации и уменьшением содержания летучих веществ.

3. Длительность свечения на первой стадии для всех марок углей совпадает с длительностью лазерного импульса $(120 \mu \mathrm{s})$. Длительность свечения на второй стадии для всех марок углей зависит от плотности энергии лазерного импульса. При $H=H_{\mathrm{cr}}^{(2)}$ составляет величину $\tau \geq 10 \mathrm{~ms}$. При увеличении $H$ до значений $6 \cdot H_{\mathrm{cr}}^{(2)}$ большая часть летучих веществ воспламеняется во время воздействия лазерного импульса. Длительность свечения на третьей стадии составляет величину 50-100 ms и практически не изменяется при увеличении $H \geq 3 \cdot H_{\mathrm{cr}}^{(3)}$.

\section{Финансирование работы}

Работа выполнена в рамках гос. задания ИУХМ ФИЦ УУХ СО РАН (проект АААА-А17-117041910150-2, руководитель Адуев Б.П.) на оборудовании ЦКП ФИЦ УУХ СО РАН

\section{Конфликт интересов}

Авторы заявляют, что у них нет конфликта интересов.

\section{Список литературы}

[1] Taniguchi M., Kobayashi H., Kiyama K., Shimogori Y. // Fuel. 2009. V. 88. N 8. P. $1478-1484$. doi 10.1016/j.fuel.2009.02.009

[2] Yang Q, Peng Z. // International J. Hydrogen Energy. 2010. V. 35. P. 4715-4722. doi 10.1016/j.ijhydene.2009.12.045

[3] Погодаев В.А. // Физика горения и взрыва. 1984. Т. 20. B. 1. C. 51-55; Pogodaev V.A. // Combustion, Explosion, and Shock Waves. 1984. V. 20. N 1. P. 46-50.

[4] Chen J.C., Taniguchi M., Narato K., Ito K. // Combustion and Flame. 1994. V. 97. N 1. P. 107-117. doi 10.1016/0010-2180(94)90119-8

[5] Воробьев А.Я., Либенсон М.Н. // Письма в ЖТФ. 1990. T. 16. B. 19. C. $79-83$.

[6] Dodoo J.N.D., Ochran A.R. // Fuel. 1994. V. 73. N 5. P. 773-778. doi 10.1016/0016-2361(94)90023-X

[7] Norman F., Berghmans J., Verplaetsen F. // Chemical Engineering Transactions. 2013. V. 31. P. 739-744. doi 10.3303/CET1331124

[8] Кузиковский А.В., Погодаев В.А. // Физика горения и взрыва. 1977. Т. 13. В. 5. С. 783-788; Kuzikovskii A.V., Pogodaev V.A. // Combustion, Explosion, and Shock Waves. 1977. V. 13. N 5. P. 783-787.
[9] Qu M., lshigaki M., Tokuda M. // Fuel. 1996. V. 75. N 10. P. 1155-1160. doi 10.1016/0016-2361(96)00079-8

[10] Адуев Б.П., Нурмухаметов Д.Р., Нелюбина Н.В., Ковалев Р.Ю., Заостровский А.Н., Исмагилов З.Р. // Химическая физика. 2016. Т. 35. В. 12. С. 47-47. doi 10.7868/S0207401X16120025; [Aduev B.P., Nurmukhametov D.R., Nelyubina N.V., Kovalev R.Y., Ismagilov Z.R. // Russ. J. Phys. Chem. B. 2016. V. 10. N 6. P. 963-965.

[11] Адуев Б.П., Нурмухаметов Д.Р., Ковалев Р.Ю., Крабт Я.В., Заостровский А.Н., Гудилин А.В., Исмагилов 3.P. // Опт. и спектр. 2018. Т. 125. В. 2. С. 277-283. doi 10.21883/OS.2018.08.46373.29-18;

[Aduev B.P., Nurmukhametov D.R., Kovalev R.Y., Kraft Ya.V., Ismagilov Z.R. // Opt. and Spectrosc. 2018. V. 125. N 2. P. 293-299.

[12] Тайи, Е.М., Андреева И.А. Методы анализа и испытания углей. М.: Недра, 1983. 301 с.

[13] Korotkikh A., Slyusarskiy K.V., Sorokin I.V. // MATEC Web of Conferences. 2017. Art. N 03003. doi $10.1051 /$ matecconf $/ 201711503003$

[14] Zhang DK., Wall T.F., Hills P.C. // Fuel. 1994. V. 73. N 5. P. 647-655. doi 10.1016/0016-2361(94)90003-5

[15] Канторович Б.В. Основы теории горения и газификации твердого топлива. М.: Металлургиздат, 1958. $601 \mathrm{c.}$

[16] Головина Е.С. // Физика горения и взрыва. 2002. Т. 38. B. 4. C. 25-34; Golovina E.S. // Combustion, Explosion, and Shock Waves. 2002. V. 38. N 4. P. 401-408. 